\title{
Cardiac Calcified Amorphous Tumor Presenting with Thromboembolism in a Patient Under Apixaban Treatment
}

\section{Apiksaban Tedavisi Gören Bir Hastada Thromboemboli ile Birlikte Gelen Kardiyak Kalsifiye Amorf Tümör}

\author{
(D) Tufan ÇINAR, iD Vedat ÇIÇEK, iD Ahmet Lütfullah ORHAN
}

University of Health Sciences Turkey, Sultan Abdülhamid Han Training and Research Hospital, Clinic of Cardiology, İstanbul, Turkey

Keywords: Calcified amorphous tumor, thromboembolism, apixaban

Anahtar Sözcükler: Kalsifiye amorf tümör, tromboembolism, apiksaban

A 75-year-old male patient had his first acute ischemic stroke attack two years ago. After the Holter monitoring, the patient was diagnosed with paroxysmal atrial fibrillation. Simultaneously, transthoracic echocardiographic examination (TTE) was performed, which provided mitral annular calcification without any thrombus or tumor formation within the intra-cardiac cavity. Vitamin $\mathrm{K}$ antagonist and warfarin were offered; however, the patient refused to take them. Therefore, he was prescribed a new oral anticoagulant, i.e., apixaban at $5 \mathrm{mg}$ twice a day. The patient was admitted to our neurology department due to the second ischemic stroke attack one week ago. Contrast computed tomography angiography showed non-significant atherosclerotic plaques in the right and left carotid arteries. Therefore, the patient was consulted by our department to exclude any sources of cardioembolism. TTE showed a hyper-echogenic mass located on the posterolateral mitral valve (Figure 1A). The 3D transesophageal echocardiography examination showed a hyper-echogenic mass with a diameter of $11 \times 15 \mathrm{~mm}$ that was located on the left-ventricular side of the mitral valve (Figure 1B and 1C). Cardiac magnetic resonance imaging was performed to aid the diagnosis. It revealed a mass that was compatible with a cardiac calcified amorphous tumor (CAT) (Figure 1D). The patient underwent cardiac valve surgery, including tumor resection due to thromboembolism (Figure $1 \mathrm{E}$ and $1 \mathrm{~F}$ ). Pathological examination confirmed the diagnosis of cardiac CAT.

CAT is an extremely rare non-neoplastic cardiac tumor, which is pathologically characterized by calcification and amorphous fibrinous material (1). CAT is usually asymptomatic, and it is incidentally detected with cardiac imaging (2). However, as in our case, CAT should be considered in the differential diagnosis of patients who present with acute ischemic stroke due to thromboembolism. Additionally, our case demonstrates that when this tumor is present, apixaban treatment may be ineffective for preventing thromboembolism in such patients.

Address for Correspondence: Tufan ÇINAR, University of Health Sciences Turkey, Sultan Abdülhamid Han

Received: 24.10 .2020 Training and Research Hospital, Clinic of Cardiology, İstanbul, Turkey E-mail: drtufancinar@gmail.com ORCID ID: orcid.org/0000-0001-8188-5020

Cite this article as: Çınar T, Çiçek V, Orhan AL.Cardiac Calcified Amorphous Tumor Presenting with Thromboembolism in a Patient Under Apixaban Treatment. Bezmialem Science 2022;10(1):104-5 


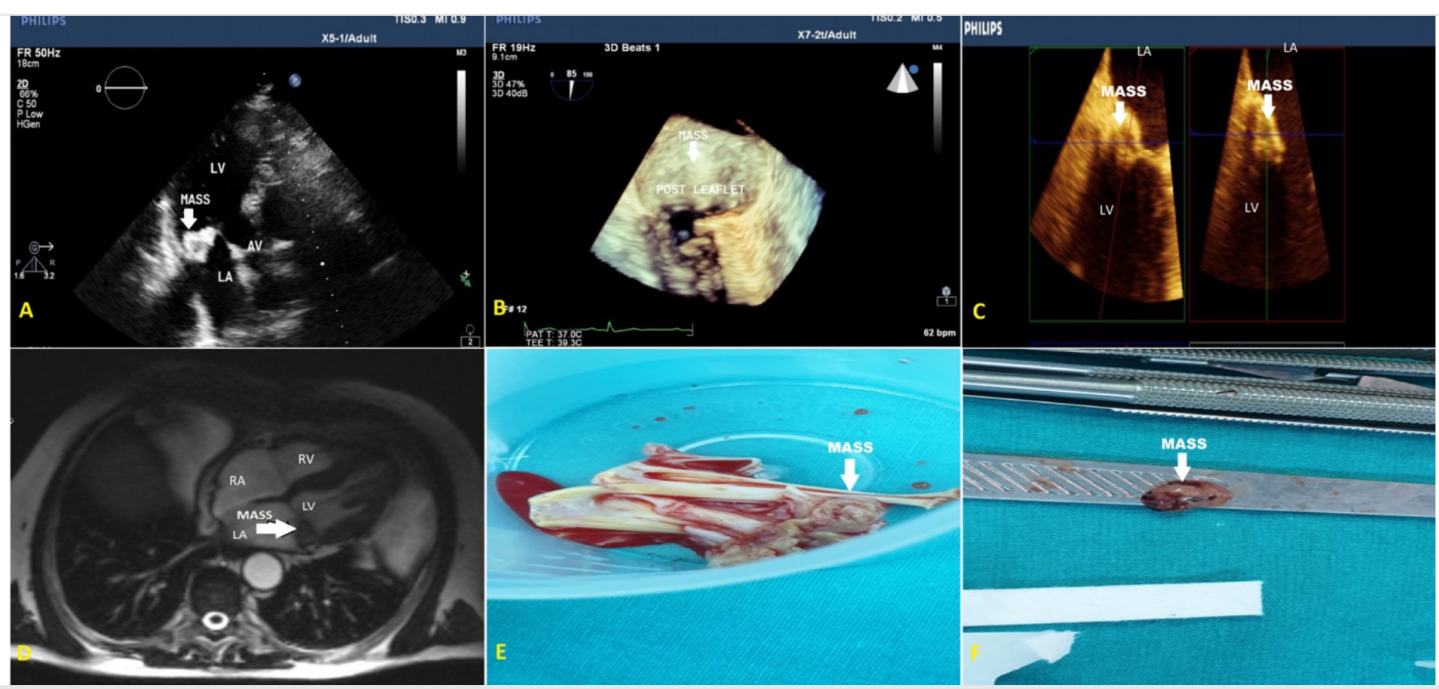

Figure 1. A-) Transthoracic echocardiography showing a hyperechogenic mass on the left ventricle side of the mitral valve, B and C-) 3-D Transosefageal echocardiography showing a hyperechogenic mass located on the posterolateral leaflet of the mitral valve, D-) Cardiac magnetic resonance imaging showing a mass which was compatible with calcified amorphous tumor, E-F) Pathological specimens showing a cardiac calcified amorphous tumor

\section{References}

1. Choi EK, Ro JY, Ayala AG. Calcified amorphous tumor of the heart: case report and review of the literature. Methodist Debakey Cardiovasc J 2014;10:38-40.
2. Fujiwara M, Watanabe H, Iino T, Kobukai Y, Ishibashi K, Yamamoto $\mathrm{H}$, et al. Two cases of calcified amorphous tumor mimicking mitral valve vegetation. Circulation 2012;125:e432- 